Article

\title{
Foundations of Banking Origin and Social Rating Philosophy-A New Proposal for an Evaluation System
}

\author{
Antonio Minguzzi ${ }^{1, *}$, Michele Modina ${ }^{2}$ and Carmen Gallucci ${ }^{3, *}$ \\ 1 Department of Bioscences and Territory, University of Molise, 86100 Campobasso CB, Italy \\ 2 Department of Economics, University of Molise, 86100 Campobasso CB, Italy \\ 3 Department of Management \& Innovation Systems, University of Salerno, 84084 Fisciano SA, Italy \\ * Correspondence: minguzzi@unimol.it (A.M.); cgallucci@unisa.it (C.G.)
}

Received: 30 April 2019; Accepted: 21 June 2019; Published: 27 June 2019

check for updates

\begin{abstract}
Social impact investments represent a cultural revolution, as they offer the opportunity to pursue financial and social goals simultaneously. However, Social impact investing market configurations are not evolving equally across national contexts. Therefore, in different contexts, different actors may play the pivotal role to make social impact investments more attractive. The present work, by looking at the Italian context, applies a qualitative methodology to study Foundations of Banking Origin (FBOs). This is a specific category of foundation which is bound by law to work and expand the charity sector. It emerges that the role of these entities, inside the philanthropy system, should develop from "impact facilitators" to "impact generators" in promoting social initiatives. Furthermore, the work sustains the importance of introducing a social impact rating system as a formalized methodology to select and finance the worthiest social project. In this perspective, the definition of a clear social rating philosophy and its correct application in the rating system design and use is a necessary condition to increase the solidity of a social impact assessment model.
\end{abstract}

Keywords: social impact investment; social rating philosophy; foundations of banking origin; mission related investment

JEL Classification: G21; G24

\section{Introduction}

In recent decades there has been an enormous growth in financial markets that has largely exceeded the value of real industrial production. Consequently, part of the created financial value has been directed towards the social system, by combining the ability to create financial value with the creation of social value. Moreover, while in origin caring social development was a philanthropic activity, since the 2000s financial scholars have begun to take interest in the issue in a new field of investigation: social finance [1-4]. In this field, social impact investing (SII) emerges as a specific branch [5], in which social objectives and economic returns coexist [6]. However, social impact investing market configurations are not evolving equally across national contexts. Therefore, the growing interest in SII is on the actors, on the principles and on the models that govern the collection, the allocation and the management of resources designed to meet social needs. Looking at the practice, it emerges that in different contexts, different actors may play a pivotal role to increase the spread of social impact investments. The present work, by looking at the Italian context, focuses on Foundations of Banking Origin (FBOs), which represent the main operators of philanthropy in Italy. They are 88 private, autonomous and non-profit entities which exclusively pursue social utility purposes, 
by using the profits deriving from financial investments to contribute to socio-economic development through the financing of social projects. Born with the aim of separating banks' credit activity from philanthropic activity, to date FBOs represent important institutional investors. At the end of 2017, their accounting assets were $€ 39.8$ billion and $94.2 \%$ were financial assets. Such assets are invested, to pursue FBOs' mission, in activities whose purpose is social utility (Mission Related Investment-MRI). MRIs are rapidly developing and have reached almost the value of 5 billion euros a year. Through MRIs, FBOs provide third sector operators also medium/long-term investments and not only direct disbursements [7]. Therefore, through this new investment tool, FBOs' role has been changing by "impact facilitator" to "impact generator". Put differently, FBOs not only support projects proposed by others but become "policy makers" of progress and of the social innovation of a specific context.

As the impact of FBO's activities is measured in both financial and social terms simultaneously, this calls for new evaluation metrics that overcome the classic risk-return dichotomy and introduce the dimension of the social impact that the investment is able to create. Therefore, drawing on the social rating philosophy [8] and inspiring from credit rating and sustainability ratings, the work proposes a social impact rating system able to mix quality parameters with social content with financial metrics. We suggest that a such rating cannot be a black box, but should be able to raise the quality and robustness of the decision making process by reducing the complexity of analyzing the attractiveness of investments and reducing the cost of financing for the best-rated projects thanks to the application on a reward mechanism. Additionally, consistent with the rating philosophy, the metrics should be unique and subject to annual review. Finally, a social rating system requires the presence of an independent evaluator that guarantees on the independence and usefulness of the judgments. In this way, it may reduce information asimmetry problems between investors and recipients.

The work makes some contributions to theory and practice. First, it enriches the current debate on social finance, specifically by focusing on SII. Second, grounded in the Italian context, it emphasizes the new role of "impact generator" played by the Foundations of Banking Origin. Third, it depicts the features, actors and challenges of a social impact rating system, by providing useful insights for practitioners.

The paper is structured as follows. The next section presents the review on the existing literature related to the actors and metrics used in social impact investment. In the third section, there is an analytical description of the characteristics and role of Italian Foundations of Banking Origin. Particular attention is devoted to the introduction of MRI. The fourth section provides an overview of the key features of the social impact rating system which reflect, in our view, the optimal rating philosophy. Finally, some concluding remarks are presented.

\section{Social Impact Investing: Actors and Outcomes Measurement}

Social impact investing, stemming from the social and sustainable finance literature [1-4], has recently been gaining widespread recognition [5]. The number of specialized conferences and publications is increasing [1,8] by both academics (among others [6,9-15]) and practitioners [16-19]. The major reason that drives the market and institutional interest in social impact investing is that investors can pursue financial and social goals simultaneously [20]. Indeed, although the social impact investments are primarily directed to the generation of a positive social impact, the innovative financial structures used to implement them assure they are both sustainable and lucrative [9,21-24]. Put differently, investors may seek ROI (return on investment) and SROI (social return on investment) at the same time [25]. This represents a cultural revolution and a shift from output-based investments to outcome-based investments, which can determine tangible and durable changes in a given context [26,27]. Short-term outputs are finalized to create medium-long term behavioral, institutional and social outcomes, a phenomenon defined as social value generation.

The process starts with a proper identification of the social problem to address (the social impact goal), then it comes the definition of why the identified problem is socially relevant, finally the ways in which the problem could be solved and the envisioning of the future beyond the intervention are 
hypothesized [28]. The theory of change (ToC) is a useful strategic approach to identify a social impact goal, to explain the causal connection between outputs and outcomes, to define measurable impact indicators, and to evaluate the overall intervention $[29,30]$. The actors involved in the process, which may pool capital, are several [15]: banks [22,31,32], banking foundations and Foundations of Banking Origin [9], institutional investors [33], governments [23,34-38], crowdfunding platforms [39,40] and high net worth individuals [41-44]. A way to categorize them may be on the basis of the correlation between impact objectives, financial returns and the strategic approach adopted, as suggested by Grabenwarter and Liechtenstein [45]. The authors identify four main categories of capital provider. Strategic Benevolents adopt a highly strategic approach, but they are very little concerned about financial returns. Double Enhancers take a highly strategic approach, but they are much more interested in achieving social objectives with financial returns. Social Business Angels adopt a low strategic approach and do not take seriously into account the financial aspects of the interventions. Finally, there are actors which adopt a less strategical approach but look at the balance between social impact and financial returns.

Although the aforementioned are the main donors, a generalization is not reachable, as recent studies suggest that SII market configurations are not evolving equally across national contexts. There are countries in which SII market is moving towards more systemic configurations, while there are others in which SII interventions left poor room for experimentation and risk-taking [46]. Therefore, in different contexts, a different actor may play a pivotal role. In the Italian economy, for example, as recently described in the latest ACRI (Associazione di Fondazioni e di Casse di Risparmio) annual report [47], FBOs represent prominent actors. Their interventions range from pure philanthropic activities, such as providing capital to fund cultural initiatives, to financial provisions in favor of third-sector organizations which act as service providers in tackling relevant social and health issues.

Another important role is played by the social rating agencies (SRAs) that exert relevant influence in bringing together stakeholders in society, investors and firms and encouraging them to dialogue about broader societal issues [48]. They also suggest measurement scales that could cover both financial outputs and social outcomes to measure the 'impact' of impact investing. This is a theme of debate and still unsolved [15,49-52]. As social impact investments extend in an atypical manner the investments' traditional trade-off between risks and returns [53], by stretching the notion of "worthy" intervention, financial parameters may be no longer the sole measure to look at to evaluate deals. Some attempts have been made to standardize impact measurement procedures and indicators and difficulties still arise when the social effects of an intervention are more suitable to a qualitative type of analysis [22,54]. Among the most recent suggestions in terms of impact metrics and outcome measurement there are the Impact Reporting and Investment Standards and the Global Impact Investment Rating System (GIIRS). Dey and Gibbon [55] examined recent trends in scientific literature on social impact measurement and noted how the main emerging themes are the development of alternative theoretical perspectives, the development of more detailed impact measurement techniques and the necessity to obtain empirical insights from studies of implementation. Furthermore, in a variety of fields within and beyond the accounting literature, attention was also devoted to SROI and balanced scorecards [56] implementation. The SROI is a measure of social return for each unity of capital invested into socially relevant initiatives which could help practitioners to make more informed decisions when considering social entrepreneurship projects. As a synthetic indicator, it can be adopted easily to evaluate interventions, thus improving accountability of public services provisions. However, SROI only partially satisfies the transition to a three-dimensional model, which takes into account risk, return and social impact simultaneously. As a synthetic indicator, SROI is an interesting measure, but it tends to favor quantitative elements that are hard to extract and, therefore, to evaluate when social initiatives do not present strong structural elements. Even though its focus on quantitative data may enhance measurement of social impact generated, SROI may actually hinder broader social accounting and audit (SAA) procedures and exclude the adoption of more qualitative parameters from evaluation processes [57]. The SROI score, despite its limitations, still represents one of the most 
rigorous evaluation techniques for assessing social impact since it constitutes the basis for ensuring accountability, it informs future decision-making processes, and it allows measurement of critical impact in by minimizing both costs and time invested in the process [58]. Castellas et al. [59] pointed out the emerging need of the Australian social impact investing market of matching capital demands of social enterprises with the private investor's funding logic. The types of social firms that might emerge may be determined based on a profit-oriented investment logic rather than on a socially-oriented logic. Syrjä et al. [60] proposed a framework to choose the most suitable performance tool based on the specific context. Performance tools should: be tailored on key stakeholders towards which social organizations should be held accountable, be consistent with the internal or external information needs, and be cost-consciously implemented.

As the role and importance of social impact investment actors into the social finance supply chain changes, so does performance measurement tools should change accordingly based on the recipient of the information. Additional controlling frameworks which consider multiple dimensions of social enterprises performance management are based upon the joint consideration of traditional financially-oriented measures, socially-oriented outcome indicators and institutional legitimacy. Furthermore, impact investment interventions were also studied using holistic frameworks such as that of McLoughlin et al. [61]. Their SIMPLEs (social impact for local economies) measurement model allows local communities' practitioners to follow through the entire socially-relevant initiative from the conceptualization of the problem to intermediate and final measurement and reporting. According to Cash [62], a word of caution is also necessary when examining the arising need for reporting in the sustainable finance landscape. The interconnections among credit rating agencies and the actors of the sustainable finance movement, in fact, may become dangerous for investors, as demonstrated by the recent financial crisis. That is because rating companies' culture often leads them to side against investors and beside the debt issuers. Moreover, according to recent literature [63], investors should decide to lend or invest their resources in double or triple-bottom enterprises only if these can ensure higher returns when compared to traditional portfolio diversification choices. Muñoz-Torres et al. [64] offered another interesting contribution by examining the role of environmental, social and governance (ESG) rating companies in the emerging social impact investing market. The authors affirm that, since ESG rating companies are mainly, although not exclusively, concerned about short-term results, they tend to look favorably at sustainable business models that focus on stakeholder's current needs. Another significant contribution is that of Nicholls [65], who conducted an empirical study of 92 SROI reports and 14 key informant interviews to build a general theory of social impact measurement which considers two materiality issues of social impact accounting: the uncertainty surrounding material data and the dynamics put in place to ensure end-user stakeholder participation. Bengo et al. [66] offered some interesting considerations for what concerns the evolution of the financial supply chains of social impact investing and on the role that impact metrics and indicators may play in the process. Since the social business market is strongly characterized by dynamic and complex relationships, the influence that each category of social impact investment actors will exert in the financial supply chain of social impact investing will also determine the change in measurement approaches implemented in the deals. If more traditional financial market actors and institutions will be able to play a major role, it may be inferred that a more financial-oriented logic will prevail over a more socially-oriented logic. By contrast, if the leading role will be that of social business organizations, then it is more likely that measurement processes will be less concerned about financial gains and metrics.

\section{The Role of Foundations of Banking Origin (FBOs) in the Field of Philanthropy in Italy}

\subsection{The Origin of the $F B O$}

In Italy, the FBO system consists of 88 foundations originally made up of banks and savings banks to exercise direct philanthropy. In the 1990s, however, the Italian legislature intervened with a series of regulations aimed at creating favourable conditions for the aggregation of the numerous small 
banks which at the time made up the system in a smaller number of operators that had a larger size. Therefore, the foundations have become the owners-rather than subsidiaries—of banking institutions to protect the aggregation of the system itself and to guarantee the stability of the property which was initially both private and public (Amato Law No. 218/90). Subsequently, the role of the FBOs (Ciampi Law No. 461/1998 and Legislative Decree 153/1999) with the aim of separating the credit activity of the banks from the philanthropic activity has been specially structured. The FBOs have been assigned the task of remaining important institutional investors (in the portfolio they still have over $30 \%$ of the national banking system today) and of using the profits of financial investments for the socio-economic development of places of settlement through the supply of philanthropic resources to the system of third sector operators (Non-Profit Organisation-NPO) and to public institutions. FBOs cannot make donations to commercial enterprises and have been defined by the Constitutional Court (sentence No. 300/2003) as "private subjects, non-profit, participating in the construction of the common well-being". The FBO, despite being private individuals, are subject to the supervision of the Ministry of Economy and Finance (MEF) with which a memorandum of understanding was defined in 2015 to self-reform the statutes of the FBO in order to institutionally strengthen the role of institutional investors and regulate the processes of financial disbursement and commonly regulate governance.

Finally, the 88 Italian FBOs are private, autonomous and non-profit entities which exclusively pursue purposes of social utility, collective interest and economic development of their region through the resources generated by the prudent investment of financial assets.

\subsection{System Size and Operational Constraints}

At the end of 2017, FBO accounting assets reached a total of $€ 39.8$ billion and $94.2 \%$ were financial assets, thus confirming the role of the foundations as an important institutional investor in the country. The set of assets of the FBOs generated 2.1 billion euros in profits, resulting in a gross profitability of $5.3 \%$. Net of total taxation (equal to 487 million euros) the FBOs set aside 474 million in equity reserves and allocated 1078.7 million in direct disbursement activities. In 2017, 19,860 interventions were financed with an average amount of 49,576 euros and an average annual number of transactions equal to 231. The main areas of intervention are, in order: art and cultural heritage, social assistance, research and development, volunteering, philanthropy, education and training, local development [47].

The important role of institutional investor played by the FBOs emerges and requires them to invest the assets in compliance with the principles of prudence and diversification, "in order to preserve their value and obtain adequate profitability". In more direct terms the constraints imposed on investment activities are the following: (a) prohibition against investing more than $15 \%$ of its assets in real estate to be allocated to income; (b) prohibition against investing more than one third of the assets of the FBO in a single company; and (c) prohibition against holding the majority of an investee company.

The combination of these constraints is aimed at preventing a Foundation from being involved in the governance of the companies in which it invests and which adequately diversifies its assets in order to preserve and defend the role of "pure" investor capable of obtaining the profitability necessary to feed philanthropic activities.

The only exception to this line is allowed if the foundation considers it essential to have a company (or foundation) as a vehicle to achieve its institutional goals in a certain relevant field of its mission. In this case it can create an "instrumental" company (or a foundation) of which it can also own $100 \%$ of the capital since it is an instrument of its institutional activities. The process of setting up the instrumental company is more complex because it requires the acceptance of the assembly (general council) of the foundation and the subsequent disclosure to the MEF. A typical case of instrumental companies are companies for local development, proposed by some FBOs to offer real services to the territory, and instrumental foundations, established for the management of museums and archives owned by the FBOs. 


\subsection{The FBO Operating Model}

The direct financial support activity of the FBOs to the NPOs is, therefore, a function of the financial profits made by the foundation in the previous year. The net annual profits become the resources available to donate charities to the NPOs in the following year. This very simple and direct financial circuit is represented by line 3 for investments and line 1 for donations (Figure 1).

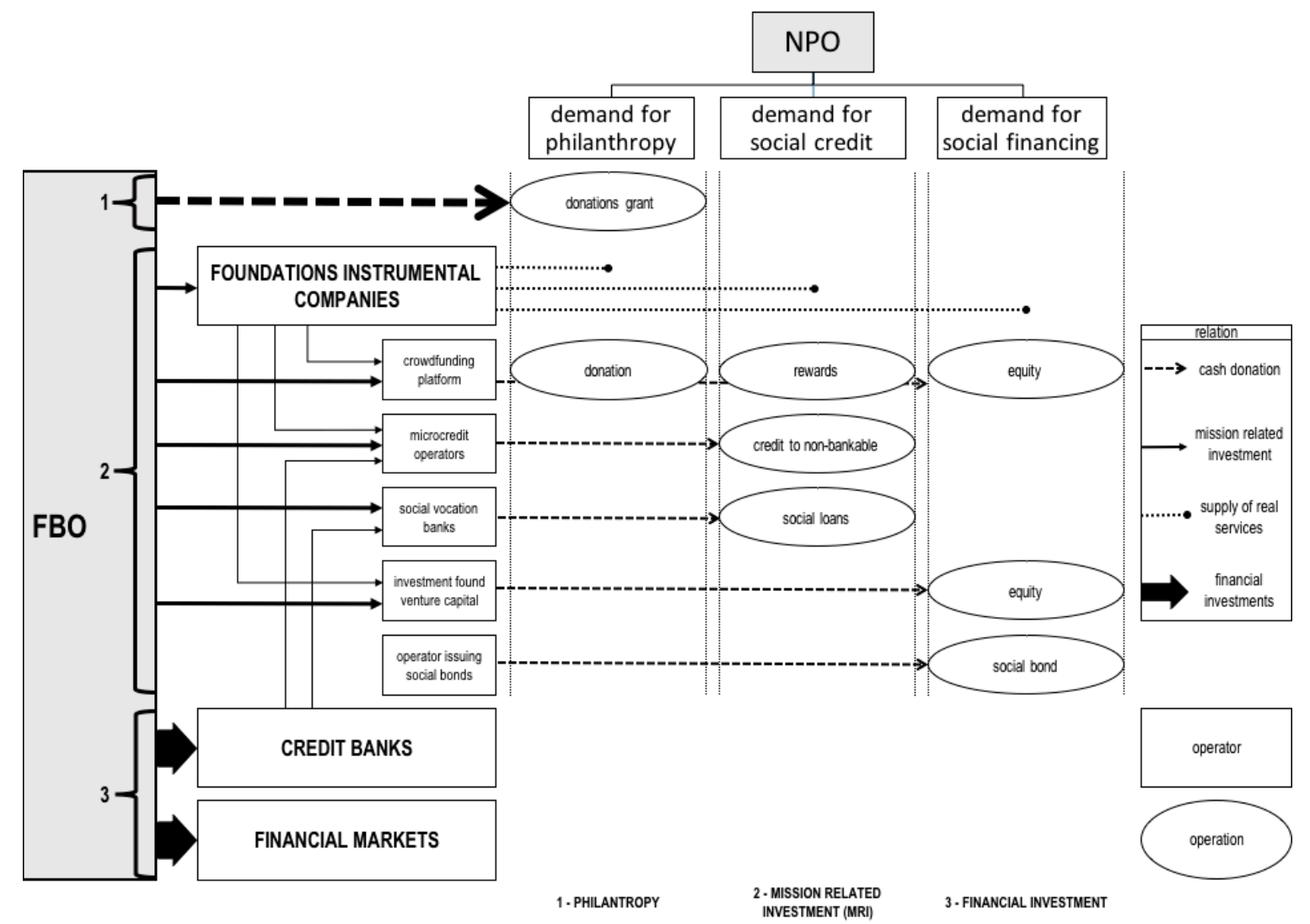

Figure 1. Foundation of Banking Origin (FBO) and stakeholder relations (Source: Our elaboration).

But if the total amount of resources available to finance the charity derives from a "quantitative" parameter (the financial profits of the previous year) the criteria with which the donations are assigned depend on "qualitative" parameters. Each foundation draws up its own regulation based mainly on the descriptive evaluation of the social benefit to be obtained through projects that need to be financed in relation to the sector to which it belongs (disability, education, culture, etc.). Usually a commission of independent members evaluates, in addition to the project, the past history of the NPO that requires a donation. At the moment there are no regulations, laws or parameters valid for all FBOs to be applied uniformly.

However, the described activity, which mainly characterizes the life of the FBOs, only satisfies the demand for short-term philanthropy of the NPOs and does not allow supporting other important moments of NPO development that occur when the social project has medium-long term goal and therefore expresses "domand for social credit" or "domand for social financing". In order to satisfy these social needs, without violating the constraints that the law places on the FBOs to preserve their heritage, the foundations can develop medium-long term initiatives through the "instrumental companies" or through the use of patrimonial investments expressly classified and authorized as MRI (line 2 Figure 1).

This means that no longer considering the assets simply as an asset which generates the resources for the supply activity, but also as a tool for the pursuit of its mission by carrying out investments in 
activities instrumental to the objectives of social utility (MRI). In Figure 1 the MRIs are represented by line 2 which summarises the main ways in which they can be carried out.

The MRIs, therefore, represent a further tool through which FBOs overcome the simple disbursement and multiply the effect of their action with respect to the NPOs which become receivers not only of direct disbursements, but also of medium/long-term investments that pursue the sustainability conditions of the interventions which meet more structural needs for their development.

From an operational point of view, MRIs are mainly implemented through investments—or co-investments-in instrumental subjects and companies which supply products/services that are dedicated to NPOs such as social credit offered by specialized banks, microcredit, crowdfunding, and investment founding activities for the third sector, social incubators, social housing, research and technology transfer [9]. The FBO trade association estimates that MRIs reached the sum of 4.6 billion euros in 2017, thus representing about $11 \%$ of the total assets of the system.

Ultimately through the MRI the FBOs invest part of their assets in assets which combine the indispensable remuneration of the assets with the support and promotion of initiatives dedicated to the pursuit of socially useful purposes and to promoting economic development. It is clear that this strategy also produces multiplicative effects due to the simultaneous satisfaction of mission and profit-making objectives which will fuel future payments. These investments also start important processes of cultural and social growth in the reference communities.

Definitely MRI allows the FBOs not only to be providers for supporting projects proposed by others but to become "policy makers" of progress and of the social innovation of the territory.

\section{The Importance of a Social Rating Philosophy}

\subsection{FBO's Role, Financial Architecture and Social Impact Measurement}

As described in the previous paragraph, the FBOs are taking on a more significant role in the social ecosystem passing from grant-maker, which supports NPO activities through direct liberal contributions, to policy makers that actively work in support of social business initiatives within of the territory in which they operate.

Through an articulated architecture that envisages the use of several forms of intervention (philanthropy, mission-related investments, and financial investments), multiple channels (direct, instrumental companies, banks, financial markets) and multiple instruments (grants, social loan, social bonds, equity), the FBO finances heterogenous activities satisfying the various requests for intervention that come from NPOs (demand for philanthropy, demand for social credit and demand for social finance).

In the new financial design, the role of the FBO passes from the impact facilitator to the impact generator. The evolution drives the transition towards a more systematic scheme (the logic of social impact) that virtuously mixes the peculiarities of some financing instruments used in social finance. The new financing structure groups together the peculiarities of the innovative models of financial investment (i.e., social bond grant/loan based, crowdfunding, social impact bond, venture philanthropy) and gets the right to be completely included in the SII framework in accordance with the paradigm of the social impact, performance and risk.

In the construction of a new financial architecture, a central element is represented by metrics systems that are functional in transmitting to all the stakeholders involved the necessary information about the goodness of the project. This need is becoming increasingly important considering the introduction of new financing models (crowdfunding, social bonds, ...) to support social initiatives and the growing role that actors such as FBOs can have in light of the emerging approach.

This includes the construction of a system of measures of social impact that is able to measure the capability of projects to create social value and, therefore, their ability to attract external financial resources [65]. In the process of creating social value, short-term results (outputs) determine behavioral, institutional and social changes (outcome) over a period of 3 to 10 years. It follows that the outcome 
must satisfy two conditions: (a) produce significant changes in the living conditions of the population and the environment that are the recipients of the social impact initiative; (b) can be verified through a counterfactual analysis, aimed at measuring what would have happened if the intervention had not been carried out.

The new financing techniques take shape when the investment follows mechanisms that combine sustainability and the economic return on investment: capital becomes a means that favors the achievement of a social objective. In a traditional investment, the dimensions examined are twofold: risk and return. In investment decisions, the allocation of invested capital meets the desired risk-return profile. The higher the expected return, the greater the risk appetite of the investor.

Social impact investment is a category of investment in which the financial parameters cannot be the only reference variable. Since this category of investment surpasses the traditional risk-return binomial, social impact configures a third essential dimension in the evaluation of investments. If traditional finance suggests considering only the trade-off between risk and return, in SII it is necessary to introduce the dimension of the social impact that the investment is able to create. This will induce investors to consider as worthy even those investments with returns in line with or below those of the market that permit the generation of measurable social impacts (outcome).

Thus, it is necessary to transition from a two-dimensional model à la Markowitz, in which the average yield and the standard deviation of the return constitute the axes that guide investment decisions, to a three-dimensional modeling in which the third variable takes on social connotations.

The currently proposed measures, such as the SROI, only partially satisfy the transition to a three-dimensional model. As a synthetic indicator, SROI is an interesting measure, but it tends to favor the quantitative elements that struggle to extract and, therefore, to evaluate when social initiatives do not present strong structural elements. In the dissemination of SII, FBOs that, despite having a typically financial origin, are an organization with a strong social vocation, play a central role. Therefore, the measurement system must suitably mix quality parameters with social content with financial metrics. In this perspective, the SROI cannot be the ideal assessment tool. A social impact rating system, which incorporates some of the characteristics of the rating model applied in the banking sector requiring identifiable mechanism and specific scaling procedures (quantitative, qualitative or both) can, in our opinion, better meet the necessary requirements of an evaluation system to be applied in the social sphere and, therefore, contribute to improving the selection process of social projects by banking foundations.

\subsection{Toward a Social Impact Rating System}

The first step in building a measurement system is the determination of its philosophy. It is very important to define the kind of information the rating intends to summarize [66] and, therefore, to understand whether the rating systems must be more quantitative-oriented, qualitative-oriented, or follow a mixed approach. As stated by Rikkers and Thibeault [8], without knowing the rating philosophy it is difficult either to interpret whether the rating models match the (pre)defined philosophy, and what the consequences are of using a model with a specific philosophical basis.

The rating philosophy must consider the objectives that the rating aims to fulfill, the assigned functions and the economic and social elements which must be considered in the rating process. In this perspective, the rating philosophy influences the design of rating systems, its mechanism and the use of the rating system. The optimal rating philosophy is determined by the rating objectives of the actors involved. The choice for rating philosophy is a trade-off between completeness, timeliness and potentiality. Whatever the rating philosophy chosen, having a clear evaluation philosophy and understanding the consequences is very important because, when combined with the quality of the non-profit organization (NPO) and its social project, it will determine the frequency of rating changes in an evolving economic and social environment.

The construction of the social rating can draw inspiration from three recently established rating systems: on the one hand, the internal rating systems (or credit rating-CR) introduced by banks in 
assessing creditworthiness and, on the other, the environmental, social and governance (ESG) rating and corporate social responsibility (CSR) rating.

The credit rating is one of the main financial innovations of the last decades. It has favored the passage from a binary logic (grant or not to grant the loan) to a multidimensional approach that influences the conditions of the financing. Its introduction redesigns the content of the relationship between lenders and borrowers by requiring both actors to achieve a cultural leap (that is not yet fully expressed). At the same time, bank rating models have passed the robustness test linked to the financial crisis. Having been built during periods of relative economic stability, before 2008 there was no direct evidence of credit risk measurement and sensitivity to the business cycle [67]. Although there is no unanimous judgment regarding the existence of a relationship between the introduction of the rating and the worsening of the already difficult economic conditions, new solutions have been sought to strengthen the foresight of the credit rating along longer time horizons. Among these, there is the combination of the traditional quantitative variables of qualitative variables that more carefully assess, for example, the attitudes of companies towards the theme and the principles of sustainability.

While credit ratings represent consolidated instruments and processes of international financial markets for the assessment of issuer default risks, the objective of sustainability ratings, both CSR and ESG, is to evaluate companies and projects based on ethical, social and/or ecological criteria. In the sustainability rating system there are some common elements although the levels of heterogeneity are high. The reason for the diversity is explained by the extent of the reasons behind the action of the providers and by the lack of a common perception about the concept of sustainability [68]. In the process of assessing corporate sustainability performance, each supplier uses its own research methods. Escrig-Olmedo et al. [69] show that, although ESG assessment models have integrated new environmental and governance criteria (e.g., effort of reduce emission, consumption) to better measure business performance, they do not yet fully integrate sustainability principles in the corporate sustainability assessment process. At the same time, it is necessary to consider that both CSR and ESG measures and reporting focus more on the output than on the social impact [65].

\subsection{The Social Impact Rating System Framework}

To give insight in the rating philosophy concept, we provide an overview of the key features of the social impact rating system that reflects the optimal rating philosophy.

\subsubsection{Social Impact Model Characteristics}

A good evaluation tool must be able to reduce the complexity of the survey areas in recognizable variables. It does not have to be a black box. Simplicity and clarity of a social impact rating system must not be misleading and meaningless. Reporting must be less ambitious, but be meaningful and have reliable data and metrics.

Because of the atypical nature of the social impact investment, it is not so easy to develop an accurate model. The use of possible risk models and input variables is limited. Models developed in other business fields cannot be used without adjustment. Default models based on public firm data will likely represent actual default risk.

A model of social impact should respect both the general characteristics of a risk model (such as powerful, accurate, statistically robust, reliable, intuitive and transparent, adhering to counterparty risk) and have its own: be farsighted; be sensitive to the socio-economic cycle; be economically efficient; be fast; be able to work only with limited data; widely applicable $[8,70]$.

In this perspective, we think that the system must provide an overall score with the rating scale ranges from 1st to 10th decile. 1st decile indicates relatively higher quality practices and relatively lower risk while a score in the 10th decile indicates relatively higher risk. The rating scale must be updated on an ongoing basis. Concerning the methodology, the system must analyze different factors, divided into defined pillars. Specific weight will be placed on each factor. Specific factors include: project relevance (level of innovation, partnership coherence, expected results coherence), project 
impact (achievement of expected results, interaction between stakeholders, community involvement), performance monitoring (SROI), and outcome (impact on the territory). Also, the methodology must be reviewed annually.

\subsubsection{Social Impact Model Function}

The design of a social score/rating system guide the project's financial viability moving in the direction of determining the attractiveness of the investment and, consequently, in its risk-return-social impact profile. This function applies to the various FBO interventions (philanthropy, mission-related investments, financial investments). The allocation of resources is influenced by the score assigned to each project. As in the case of internal rating systems adopted in the banking sector, the assignment of a good score to the social impact project accelerates the collection of funds and increases the size of the funds raised. In the proposed model, the FBO could, for example, provide more virtuous liberal contributions to the NPO on the basis of merit assigned to the project. At the same time, the introduction of ratings in the context of mission-related investments raises the quality and robustness of the decision-making process.

If in the philanthropic activity, the donation favors the social dimension of the intervention, the opening to more evolved forms of intervention requires equal attention towards the financial dimension of the investment which must not only preserve the invested capital, but also a return on investment consistent with the risk associated with it. Since the mission-related investments require the use of the assets of the FBO, they must consider not only the recovery of the invested capital, but also the generation of a surplus that will be used to support the philanthropic activity.

The social impact model enables FBOs to develop and integrate responsible investment policies and practices into their investment decisions, to inform NPOs engagements and to execute correctly upon these policies. In this perspective, it must be a decision support tool related both to the actors involved and to the purpose for which it has built.

\subsubsection{Social Impact Model Processing}

Referring to Rikkers and Thibeault [8], the risk modeling process contains three main activities, as shown in Figure 2. The starting point is the evaluation philosophy which, as previously mentioned, influences the design of rating systems (i.e., development process, type of model, type of variable), then their structure (rating models and policies) and, finally, the utilization functions which, in our case, refer to the support to investment decisions. For this reason, it is important to decide first on the rating philosophy, before developing evaluation systems.

Rating philosophy

\begin{tabular}{|c|}
\hline $\begin{array}{c}\text { Rating system } \\
\text { design }\end{array}$ \\
- Rating model \\
development \\
process \\
- Rating model \\
type \\
- Rating model \\
variable type \\
\hline
\end{tabular}

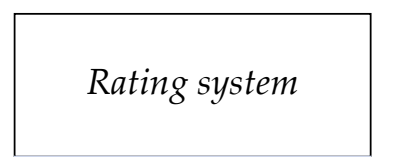

- Rating models

- Rating policies
Rating system use

- Support to

investment decision

- Reward mechanism

Figure 2. The social impact model processing (Source: our elaboration on Rikkers and Thibeault [8]). 
Just as banks finance different entities through the use of more technical forms, FBOs also finance heterogeneous activities and counterparties with different characteristics. However, the banks use the same rating model regardless of the counterparties and the methods of financing. Introducing different rating systems according to the characteristics of the NPOs could perhaps avoid the potential rigidity of the system, but it would certainly introduce elements of complexity that are so high as to make its real application in social finance almost impossible.

As regards the use of the rating system, in addition to support for the decision-making process, the proposed model favors the reduction of the cost of financing thanks to the application of a reward mechanism. For example, in the case of a mission-related investment, the financial return may be lower than expected due to the remuneration mechanism.

In the traditional pay-for-success mode, when the achievement of the minimum social objective is certified (or when the project is successful), the loaned capital is returned and, based on the results, the return on capital can vary up to the value fixed maximum. In our proposal, the achievement of the result is not reflected in the higher remuneration for the FBO, but at the lower financial cost sustained by the NPO with the best valuations. This circumstance finds its logical justification in the fact that the most virtuous project (or the one that has received a more favorable score) will produce a greater social impact (higher result). The greater social benefits generated for the community justify lower remuneration for the deserving project and encourage the adoption of virtuous behavior by the NPO.

\subsubsection{Social Impact Model Challenges}

Building on the works of Windolph [71] and Escrig-Olmedo et al. [69], Table 1 provides an overview of the main challenges related to the construction of an assessment model, their association with the different risk models examined—credit rating (CR), environmental, social and governance (ESG) rating, corporate social responsibility (CSR) rating-and their meaning. As an element of comparison, it illustrates the mitigating factors offered by our proposal.

The experience derived from the application of both credit rating (CR), environmental, social and governance (ESG) rating and corporate social responsibility (CSR) rating poses several challenges to be met:

- Multiple use. Over the course of its life, the credit rating has seen the use functions for which it was initially conceived grow, becoming in fact a multifunctional tool. The use for purposes that are often not aligned with each other and with different risk contents has determined the greater complexity of the instrument and the wide versatility of its technical characteristics-adherence to counterparty risk, sensitivity to the economic cycle, and farsightedness [72]. The social impact rating system has two only functions: to determine the attractiveness of the investment and to favor the applicability of a risk-return mechanism.

- Lack of transparency. The CR, ESG and CSR rating systems do not offer complete and public information on the criteria and the evaluation process developed by them to assess company credit or sustainability performance [69]. This makes it difficult to understand what the evaluation systems are measuring and makes it difficult to compare the different results. The social impact assessment model is not meant to be a black box. The survey areas, the variables, their weighting, the threshold values and, in general, the methodological criteria of the evaluation analysis must be known and made public in order to make the rating assignment process readable and interpretable. The greater the degree of transparency of the evaluation process, the greater will be their reliability in the eyes of both the subject evaluated and those who use the rating in the portfolio allocation of social investments.

- Lack of standardization. The rating systems applied in finance and in social responsibility may measure the same concept in different ways. Therefore, if the assessments of ratings are not consistent, which involves evidence of low commensurability, the hypothesized benefits cannot occur $[69,71]$. The standardization of the model allows both to better evaluate the methodological approach and to favor a clearer comparison of the assigned rating. 
- Lack of an overall score. Most of the ESG and CSR rating systems do not express the performance in an overall score makes it difficult to understand companies' positions and to compare them. The social impact rating system provides an overall score with the rating scale ranges from 1 st to 10th decile.

- Lack of independence. Since the assignment of the rating often requires a personal interaction between the evaluator and the subject evaluated in order to collect the necessary set of information, doubts emerge on the actual independence of the judgments and, therefore, on their degree of acceptance and usefulness [71]. In the proposed model, there is a presence of an independent evaluator.

The elements described above recommend caution in the construction of an evaluation model. Our suggestion is that the definition of a clear social rating philosophy and its correct application in the rating system design and use is a necessary condition to increase the solidity of a social impact assessment model.

Table 1. Challenges for ratings assessing social impact.

\begin{tabular}{ccll}
$\begin{array}{c}\text { Rating } \\
\text { Challenges }\end{array}$ & Rating Type & \multicolumn{1}{c}{ Meaning } & \multicolumn{1}{c}{ Mitigants of Our Proposal } \\
\hline Multiple use & CR & $\begin{array}{l}\text { Covering a series of functions } \\
\text { ranging from the } \\
\text { determination of regulatory } \\
\text { capital to the pricing policies }\end{array}$ & $\begin{array}{l}\text { The system determines the attractiveness } \\
\text { of the investment and favors the } \\
\text { applicability of better financing } \\
\text { conditions for the best-rated counterparts }\end{array}$ \\
\hline $\begin{array}{c}\text { Lack of } \\
\text { transparency }\end{array}$ & CR, ESG, CSR & $\begin{array}{l}\text { Rarely full disclosure of } \\
\text { methodology, criteria, } \\
\text { threshold values, etc. }\end{array}$ & $\begin{array}{l}\text { The social impact assessment model is not } \\
\text { a black box, but a transparent system } \\
\text { whose evaluation criteria are known and } \\
\text { made public. }\end{array}$ \\
\hline $\begin{array}{c}\text { Lack of } \\
\text { standardization }\end{array}$ & ESG, CSR & $\begin{array}{l}\text { Diversity of approaches and } \\
\text { results, no evaluation of } \\
\text { approaches, no comparability }\end{array}$ & $\begin{array}{l}\text { The methodological approach is unique } \\
\text { and is subject to annual review }\end{array}$ \\
\hline $\begin{array}{c}\text { Lack of an } \\
\text { overall score }\end{array}$ & ESG, CSR & $\begin{array}{l}\text { Missing provision of } \\
\text { an overall score }\end{array}$ & $\begin{array}{l}\text { The system provides an overall score with } \\
\text { the rating scale ranges from 1st to } \\
\text { 10th decile }\end{array}$ \\
\hline $\begin{array}{c}\text { Lack of } \\
\text { independence }\end{array}$ & CR, ESG, CSR & $\begin{array}{l}\text { Relation between rating } \\
\text { organizations and NPOs }\end{array}$ & Presence of an independent evaluator \\
\hline $\begin{array}{c}\text { CR: credit; ESG: environmental, social and governance, CSR: corporate social responsibility. Source: our elaboration } \\
\text { on Escrig-Olmedo et al. [69] and Windolph [71]. }\end{array}$
\end{tabular}

\section{Conclusions}

The present work aimed to investigate the role of the Foundations of Banking Origin in SII and to underline the need for defining a social rating philosophy functional to the construction of a robust social rating system and its consistent use. The qualitative analysis has highlighted the pivotal role that FBOs could play in creating both financial and social value simultaneously. They can not only act according to the traditional provision of money (impact facilitator), but they can also increase the promotion of initiatives dedicated to the pursuit of social utility and economic goals through a deeper selection of social project thanks to a social rating system. In this perspective, the foundations can rise to the role of "generator of social impact" since it is directly able to create social changes and generate, at the same time, sustainable economic returns for the investors. In this way, the foundations actively contribute to the development and dissemination of social finance, creating in turn a multiplier effect.

As the role and importance of FBOs in the supply chain of social finance grow, performance measurement tools must in turn evolve [73]. In our view, the evaluation of the social impact through a rating system is really crucial. Furthermore, in comparison with the general characteristics of risk models, the social impact assessment model must be able to transmit to stakeholders the necessary 
information on the capacity of the initiative to create social value, in a fast, efficient and widely applicable way. This need is becoming more important because of the introduction of new financing models (e.g., crowdfunding, social bonds) to support social initiatives and because of the growing role of actors such as FBOs.

This study makes a significant contribution to the existing literature on the evolution of social finance, offering insights on the role that new actors can play and on the importance of introducing effective evaluation systems. From a practical point of view, this document provides a contribution to satisfying the growing need of investors for having evaluation systems that respond to clear principles of economic and social sustainability. In this perspective, our findings provide indications on the characteristics, functions, processes and main challenges that must characterize an efficient social impact assessment system.

However, although these insights are interesting, the paper merely represents a starting point to further develop a social rating system. Therefore, future research could formalize, test and validate a social rating system built according to the suggestions proposed here. Additionally, by applying a multiple case study methodology, further works could better investigate the role of FBOs in SII and overcome the mainly conceptual approach of this paper. Again, it would be interesting to collect materials about the projects (MRIs) financed by FBOs and make inferences about them to deepen how efficiently and effectively FBOs use resources.

Author Contributions: The authors have contributed to the article accordingly: Conceptualization, A.M., M.M. and C.G.; Methodology, A.M., M.M. and C.G.; Writing-original draft, A.M., M.M. and C.G.; Writing-review and editing, A.M., M.M. and C.G.

Funding: This research received no external funding.

Conflicts of Interest: The authors declare no conflict of interest.

\section{References}

1. Harji, K.; Hebb, T. Impact Investing for Social Finance. In Proceedings of the ANSER Conference 2010, Montreal, QC, Canada, 2-4 June 2010; pp. 1-20.

2. Weber, O. Social Finance and Impact Investing. 2012. Available online: http://ssrn.com/abstract=2160403 (accessed on 15 March 2019).

3. Geobey, S.; Weber, O. Lessons in operationalizing social finance: The case of Vancouver City Savings Credit Union. J. Sustain. Financ. Investig. 2013, 3, 124-137. [CrossRef]

4. Hochstadter, A.K.; Scheck, B. What's in a Name: An Analysis of Impact Investing Understandings by Academics and Practitioners. J. Bus. Ethics 2014, 132, 449-475. [CrossRef]

5. Agrawal, A.; Hockerts, K. Impact investing: Review and research agenda. J. Small Bus. Entrep. 2013. [CrossRef]

6. Viviers, S.; Ratcliffe, T.; Hand, D. From philanthropy to impact investing: Shifting mindsets in South Africa. Corp. Ownersh. Control 2011, 8, 25-43. [CrossRef]

7. Presenza, A.; Tindara, A.; Minguzzi, A. Social Innovation through crowdfunding: The case of Meridonare. In Proceedings of the Sinergie-Sima 2017 Conference, Naples, Italy, 15-16 June 2017.

8. Rikkers, F.; Thibeault, A. The Optimal Rating Philosophy for the Rating of SMEs; Vlerick Leuven Gent Working Paper Series; 2007; Volume 10, Available online: https:/econpapers.repec.org/paper/vlgvlgwps/2007-10.htm (accessed on 15 March 2019).

9. Hangl, C. A Literature Review about the Landscape of Social Finance. ACRN J. Financ. Risk Perspect. 2014, 3, 64-98.

10. Nicholls, A.; Nicholls, J.; Paton, R. Measuring social impact. In Social Finance; Nicholls, A., Emerson, J., Paton, R., Eds.; Oxford University Press: Oxford, UK, 2015; pp. 253-281.

11. Schinckus, C. The valuation of social impact bonds: An introductory perspective with the Peterborough SIB. Res. Int. Bus. Financ. 2015, 35, 104-110. [CrossRef]

12. Brandsetter, L.; Lehner, O.M. Impact Investment Portfolios: Including Social Risks and Returns; ACRN Oxford Publishing House: Oxford, UK, 2015. 
13. Daggers, J.; Nicholls, A. Academic Research into Social Investment and Impact Investing: The Status Quo and Future Research. In Routledge Handbook of Social and Sustainable Finance; Routledge: Oxford, UK, 2016.

14. Lehner, O.M. Routledge Handbook of Social and Sustainable Finance; Routledge: London, UK, 2016.

15. Weber, O. Introducing Impact Investing. In Routledge Handbook of Social and Sustainable Finance; Lehner, O.M., Ed.; Routledge: Oxford, UK, 2016.

16. Saltuk, Y.; Bouri, A.; Mudaliar, A.; Pease, M. Perspectives on Progress: The Impact Investor Survey; Global Impact Investor Network (GIIN), \& Global Social Finance, J.P. Morgan: New York, NY, USA, 2013.

17. Social Impact Investment Task Force. La Finanza che Include: Gli Investimenti ad Impatto Sociale per Una Nuova Economia. 2014. Available online: http://www.socialimpactagenda.it/wp-content/uploads/2016/04/ La-finanza-che-include.pdf (accessed on 15 March 2019).

18. OECD. Social Impact Investment: Building the Evidence Base. 2015. Available online: http://www.oecd.org/ sti/ind/social-impact-investment.pdf (accessed on 15 March 2019).

19. Gonnella, C.; Cerlenco, S. La Finanza ad Impatto Sociale; Fondazione Tertio Millennio-Onlus. Ecra: Roma, Italy, 2016.

20. Rizzello, A.; Migliazza, M.C.; Caré, R.; Trotta, A. Social Impact Investing: A model and Research Agenda. In Routledge Handbook of Social and Sustainable Finance; Weber, O., Ed.; Routledge: Oxford, UK, 2016.

21. Crescentini, L.; Zaccardi, E. Investimento ad Impatto Sociale: Analisi ed Opportunità. Quaderno di Approfondimento Assoprevidenza. 2016. Available online: https://assoprevidenza.it/quaderni/investimentia-impatto-sociale-analisi-e-opportunita-2/ (accessed on 15 March 2019).

22. Jackson, E.T. Evaluating social impact bonds: Questions, challenges, innovations, and possibilities in measuring outcomes in impact investing. Community Dev. 2013, 44, 608-616. [CrossRef]

23. Wood, D.; Thornley, B.; Grace, K. Institutional Impact Investing: Practice and Policy. J. Sustain. Financ. Investig. 2013, 3, 75-94. [CrossRef]

24. Evans, M. Meeting the Challenge of Impact Investing: How Can Contracting Practices Secure Social Impact without Sacrificing Performance? J. Sustain. Financ. Investig. 2013, 3, 138-154. [CrossRef]

25. Quinn, Q.C.; Munir, K.A. Hybrid Categories as Political Devices: The Case of Impact Investing in Frontier Markets. Res. Soc. Organ. 2017, 51, 113-150. [CrossRef]

26. Crutchfield, L.R.; Grant, H.M. Forces for Good: The Six Practices of High Impact Nonprofits; Jossey Bass: San Francisco, CA, USA, 2008.

27. Perrini, F. Social Entrepreneurship. Imprese Innovative per il Cambiamento Sociale; Egea: Milano, Italy, 2007.

28. Global Social Venture Competition, GSV. 2012. Available online: https://www.iaia.org/uploads/pdf/ SIAGuidanceDocumentIAIA.pdf (accessed on 16 April 2019).

29. Zamagni, S.; Venturi, P.; Rago, S. Valutare l'impatto sociale. La questione della misurazione nelle imprese sociali. Impresa Soc. 2015, 6, 77-97.

30. Castello, S.; Lévêque, C. La Theory of Change come Impact-Model: Diffusione e Utilizzo a Livello Nazionale e Internazionale. Philanthropy Insights, 4, Fondazione Lang Italia. 2016. Available online: http://en.fondazionelangitalia.it/wp-content/uploads/2016/03/Philanthropy-Insights-n_4.pdf (accessed on 15 March 2019).

31. Burand, D. Globalizing Social Finance: How Social Impact Bonds and Social Impact Performance Guarantees Can Scale Development. N.Y.U. J. Law Bus. 2012, 9, 447-502.

32. Scholtens, B. Finance as a Driver of Corporate Social Responsibility. J. Bus. Ethics 2006, 68, 19-33. [CrossRef]

33. Dutt, N.; Ganesh, U.; Chandrasekaran, P.; Agarwal, P.; Patil, S.; Gupta, A. Invest Catalyze Mainstream: The India Impact Investing Story; Intellecap: Mumbai, India, 2013.

34. Bonini, S.; Emerson, J. Maximizing Blended Value-Building beyond the Blended Value Map to Sustainable Investing, Philanthropy and Organizations. CO, USA, 2005. Available online: http://www.blendedvalue.org/ wp-content/uploads/2004/02/pdf-maxblendedvalue.pdf (accessed on 15 March 2019).

35. Cabinet Office UK. G8 Social Impact Investment Forum Outputs and Agreed Actions; Cabinet Office: London, UK, 2013.

36. Cohen, R. Harnessing social entrepreneurship and investment to bridge the social divide. In EU Conference on the Social Economy; European Economic and Social Committee: Brussels, Belgium, 2011; pp. 1-7.

37. Thorlby, T. Are Social Stock Exchanges the Great Equalizer to Democratize Development Finance? JRF Briefing Paper: London, UK, 2011. 
38. Tjornbo, O.; Westley, F.R. Game Changers: The Big Green Challenge and the Role of Challenge Grants in Social Innovation. J. Soc. Entrep. 2012, 3, 166-183. [CrossRef]

39. Gallucci, C.; Modina, M.; Minguzzi, A. The evolution of a social service crowdfunding platform towards an investment logic: The Meridonare case study. In Social Impact Investing beyond SIB. Evidence from the Market; La Torre, M., Calderini, M., Eds.; Palgrave Macmillan: Basingstoke, UK, 2018; pp. 141-175.

40. Presenza, A.; Abbate, T.; Cesaroni, F.; Appio, F.P. Enacting Social Crowdfunding Business Ecosystems: The case of the platform Meridonare. Technol. Forecast. Soc. Chang. 2019, 143, 190-201. [CrossRef]

41. Bolton, E.; Savell, L. Towards a new social economy: Blended value through social impact bonds. In Social Impact through Effective Finance; Social Finance Ltd.: London, UK, 2010.

42. Brett, D. Aavishkaar India Micro Venture Capital Fund; Duke University Press: Durham, NC, USA, 2013.

43. Demel, A. Second Thoughts on Social Impact Bonds. N.Y.U. J. Law Bus. 2012, 9, 503-510.

44. Tzouvelekas, M. Social finance tools for cooperation and development: The cooperative banking sector as a potential pillar for impact investments in Greece. In Proceedings of the EURICSE 2014, Murcia, Spain, 27-31 October 2014.

45. Grabenwarter, U.; Liechtenstein, H. In Search of Gamma-An Unconventional Perspective on Impact Investing. IESE Business School Working Paper. 2011. Available online: https://papers.ssrn.com/sol3/papers. cfm?abstract_id=2120040 (accessed on 15 March 2019).

46. Calderini, M.; Chiodo, V.; Michelucci, F.V. The social impact investment race: Toward an interpretative framework. Eur. Bus. Rev. 2018, 30, 66-81. [CrossRef]

47. ACRI-Associazione di Fondazioni e di Casse di Risparmio SpA. Fondazioni di origine bancaria XXIII Rapporto annuale. 2017. Available online: https://www.acri.it/_upload/Rapporto/23RAPP0.zip (accessed on 15 March 2019).

48. Bernard-Rau, B.; Lauche, K.; Blazevic, V. Bridging the Gap between Society and Business: The Transformative Role of Social Rating Agencies. Acad. Manag. Proc. 2018, 1, 12083. [CrossRef]

49. Bugg-Levine, A.; Emerson, J. Impact Investing: Transforming How We Make Money While Making a Difference, 1st ed.; Jossey-Bass A wiley Imprint: San Francisco, CA, USA, 2011.

50. Nicholls, A.; Pharoah, C. The Landscape of Social Investment: A Holistic Topology of Opportunities and Challenges; Skoll Centre for Social Entrepreneurship, Said Business School, University of Oxford: Oxford, UK, 2008.

51. Saltuk, Y.; Bouri, A.; Leung, G. Insight to the Impact Investing Market: An In-Depth Analysis of Investor Perspectives; JP Morgan Social Finance-GIIN: New York, NY, USA, 2011.

52. Tekula, R.; Shah, A. Impact Investing: Funding social innovation. In Routledge Handbook of Social and Sustainable Finance; Lehner, O.M., Ed.; Routledge: Oxford, UK, 2016; pp. 125-136.

53. O'Donohoe, N.; Leijonhufvud, C.; Saltuk, Y.; Bugg-Levine, A.; Brandeburg, M. Impact Investments: An Emerging Asset Class; JP Morgan Social Finance-GIIN: New York, NY, USA, 2010.

54. Clarkin, J.E.; Cangioni, C. Impact investing: A primer and review of the literature. Entrep. Res. J. 2016, 6, 135-173. [CrossRef]

55. Dey, C.; Gibbon, J. Moving on from Scaling Up: Further Progress in Developing Social Impact Measurement in the Third Sector. Soc. Environ. Account. J. 2017, 37, 66-72. [CrossRef]

56. Meadows, M.; Pike, M. Performance management for social enterprises. Syst. Pract. Action Res. 2010, 23, 127-141. [CrossRef]

57. Gibbon, J.; Dey, C. Developments in Social Impact Measurement in the Third Sector: Scaling Up or Dumbing Down? Soc. Environ. Account. J. 2011, 31, 63-72. [CrossRef]

58. Nicholls, J.; Mackenzie, S.; Somers, A. Measuring Real Value: A DIY Guide to Social Return on Investment. Available online: https://www.eldis.org/document/A33358 (accessed on 16 April 2019).

59. Castellas, E.I.P.; Ormiston, J.; Findlay, S. Financing social entrepreneurship: The role of impact investment in shaping social enterprise in Australia. Soc. Entrep. J. 2018, 14, 130-155. [CrossRef]

60. Syrjä, P.; Sjögrén, H.; Ilmarinen, A. Performance measurement in social enterprises-A conceptual accounting approach. In Proceedings of the 5th EMES International Research Conference on Social Enterprise-Building a Scientific, Helsinki, Finland, 30 June-3 July 2015.

61. McLoughlin, J.; Kaminski, J.; Sodagar, B.; Khan, S.; Harris, R.; Arnaudo, G.; Mc Brearty, S. A strategic approach to social impact measurement of social enterprises. Soc. Entrep. J. 2009, 5, 154-178. [CrossRef]

62. Cash, D. Sustainable finance ratings as the latest symptom of 'rating addiction'. J. Sustain. Financ. Investig. 2018, 8, 242-258. [CrossRef] 
63. Viviani, J.L.; Maurel, C. Performance of impact investing: A value creation approach. Res. Int. Bus. Financ. 2019, 47, 31-39. [CrossRef]

64. Muñoz-Torres, M.J.; Fernández-Izquierdo, M.Á.; Rivera-Lirio, J.M.; Escrig-Olmedo, E. Can environmental, social, and governance rating agencies favor business models that promote a more sustainable development? Corp. Soc. Responsib. Environ. Manag. 2019, 26, 439-452. [CrossRef]

65. Nicholls, A. A General Theory of Social Impact Accounting: Materiality, Uncertainty and Empowerment. J. Soc. Entrep. 2018, 9, 132-153. [CrossRef]

66. Bengo, I.; Arena, M.; Azzone, G.; Calderini, M. Indicators and metrics for social business: A review of current approaches. J. Soc. Entrep. 2016, 7, 1-24.

67. Löffler, G. An anatomy of rating through the cycle. J. Bank. Financ. 2004, 28, 695-720. [CrossRef]

68. Bendoraitiene, E.; Gaigaliene, A. Analysis of CSR Measurement Criteria of Social Ratings System. Appl. Econ. Syst. Res. 2015, 9, 61-75. [CrossRef]

69. Escrig-Olmedo, E.; Fernandez-Izquierdo, M.A.; Ferrero-Ferrero, I.; Rivera-Lirio, J.M.; Muñoz-Torres, M.J. Socially responsible investing: Sustainability indices, ESG rating and information provider agencies. Int. J. Sustain. Econ. 2010, 2, 442-461. [CrossRef]

70. De Laurentis, G.; Maino, R. I rating interni durante e dopo la crisi: Rapporti banca-impresa, vincoli regolamentari e modelli di business. Bancaria 2010, 1, 17-30.

71. Windolph, S.E. Assessing corporate sustainability through ratings: Challenges and their causes. J. Environ. Sustain. 2011, 1, 61-81. [CrossRef]

72. Modina, M. Credit rating and new developments in bank-firm relationship. Bancaria 2012, 12, $62-67$.

73. Lingane, A.; Olsen, S. Guidelines for Social Return on Investment. Calif. Manag. Rev. 2004, 46, 116-135. [CrossRef]

(C) 2019 by the authors. Licensee MDPI, Basel, Switzerland. This article is an open access article distributed under the terms and conditions of the Creative Commons Attribution (CC BY) license (http://creativecommons.org/licenses/by/4.0/). 